\title{
Costa, sierra y selva: franjas geográficas, zonas culturales y episodios nacionales
}

Côte, Hautes terres et Amazonie

bandes géographiques, zones culturelles et

épisodes

nationaux

Coast, highlands and jungle: geographical strips, cultural areas and national episodes

Alexandre Surrallés

\section{(2) OpenEdition \\ Journals}

Edición electrónica

URL: https://journals.openedition.org/bifea/12202

DOI: $10.4000 /$ bifea. 12202

ISSN: 2076-5827

Editor

Institut Français d'Études Andines

Edición impresa

Fecha de publicación: 8 diciembre 2020

Paginación: 237-253

ISSN: 0303-7495

Referencia electrónica

Alexandre Surrallés, "Costa, sierra y selva: franjas geográficas, zonas culturales y episodios

nacionales», Bulletin de l'Institut français d'études andines [En línea], 49 (2) | 2020, Publicado el 25

noviembre 2021, consultado el 01 diciembre 2021. URL: http://journals.openedition.org/bifea/12202 ; DOI: https://doi.org/10.4000/bifea.12202 


\title{
Costa, sierra y selva: franjas geográficas, zonas culturales y episodios nacionales*
}

\author{
Alexandre Surrallés**
}

\section{Resumen}

Es este ensayo se describe el discurso, en particular antropológico, sobre la división tripartita del Perú entre costa, sierra y selva, para mostrar cómo evoluciona al ritmo de la percepción general de la sociedad peruana sobre la composición de su identidad, donde la Amazonía ocupa ahora un espacio inesperado hasta hace pocos años. Debida entre otras causas a la migración y la concientización ecológica, esta irrupción de la selva en el Perú actual ha supuesto algo que muy bien podríamos llamar una revolución cultural amazónica, de naturaleza parecida, pero con distintos ingredientes, a la revolución cultural andina durante el siglo pasado. Esto llevará a abordar el asunto de las relaciones Andes-selva tan importantes en la antropología actual, y del rol de la costa entre ellas, tema fundamental, pero apenas considerado.

Palabras clave: Amazonía, integración, costa, pueblos indígenas, nación

\section{Côte, Hautes terres et Amazonie : bandes géographiques, zones culturelles et épisodes nationaux}

\section{Résumé}

Cet essai décrit le discours, en particulier anthropologique, sur la division tripartite du Pérou entre côte, Andes et forêt, pour montrer comment il évolue au rythme de la perception générale de la société péruvienne sur la composition de son identité, où l'Amazonie occupe une place inattendue jusqu'à

* Este artículo es el resultado de un diálogo con los conferenciantes y el público en general de una presentación que realicé en el marco del coloquio internacional Siguiendo el sol, surcando el río: las relaciones entre la selva y la costa en la región andina (9-10 de abril del 2015), dirigido por Alejandro Diez Hurtado y yo mismo, y organizado por la Pontificia Universidad Católica del Perú y el Instituto Francés de Estudios Andinos-IFEA (ver Surrallés, 2015, para un resumen de los contenidos tratados). Aprovecho para agradecer a los dos lectores anónimos por sus recomendaciones.

** Directeur d'études, EHESS, Directeur de recherche, CNRS. Laboratoire d'anthropologie sociale, Collège de France. E-mail: alexandre.surralles@ehess.fr 
il y a quelques années. En raison, entre autres, des migrations et de la conscientisation écologique, cette irruption de l'Amazonie dans le Pérou actuel a signifié ce que I'on pourrait très bien appeler une révolution culturelle amazonienne, de nature similaire, mais avec des éléments différents, à la révolution culturelle andine du siècle dernier. Cela amène à aborder la question des relations AndesAmazonie, si importantes dans l'anthropologie actuelle, et le rôle de la côte parmi elles, une question fondamentale mais peu prise en compte.

Mots-clés : Amazonie, intégration, côte, peuples autochtones, nation

\title{
Coast, highlands and jungle: geographical strips, cultural areas and national episodes
}

\begin{abstract}
Es este ensayo se describe el discurso, en particular antropológico, sobre la división tripartita del Perú entre costa, sierra y selva, para mostrar cómo evoluciona al ritmo de la percepción general de la sociedad peruana sobre la composición de su identidad, donde la Amazonía ocupa ahora un espacio inesperado hasta hace pocos años. Debida entre otras causas a la migración y la concientización ecológica, esta irrupción de la selva en el Perú actual ha supuesto algo que muy bien podríamos llamar una revolución cultural amazónica, de naturaleza parecida, pero con distintos ingredientes, a la revolución cultural andina durante el siglo pasado. Esto llevará a abordar el asunto de las relaciones Andes-selva tan importantes en la antropología actual, y del rol de la costa entre ellas, tema fundamental, pero apenas considerado.
\end{abstract}

Keywords: Amazonia, integration, coast, indigenous peoples, nation

\section{INTRODUCCIÓN}

Por encontrarse en los frontispicios de toda escuela nacional, el escudo peruano es el símbolo estatal más extendido y, en muchas ocasiones, el único signo de la existencia de la nación en los lugares más remotos del país. La simbología oficial afirma que las imágenes que aparecen en el escudo representan las riquezas que posee el Perú en los tres reinos naturales: la vicuña se refiere al reino animal, el árbol de la quina evoca las riquezas del reino vegetal y la cornucopia representa los acervos mineros del Perú. En muchos lugares de la Amazonía, y quizá en otras partes del Perú, piensan sin embargo que el escudo representa los tres componentes geográficos en los que se supone se divide el país: el árbol representa la selva, la llama representa la sierra y el molusco representa el mar. En cualquier caso, lo que prueba esta falsa pero extendida interpretación popular es el apego que se le tiene a esta división costa, sierra y selva, descrita ya por los primeros cronistas coloniales como Cieza de Léon, siempre con base en criterios sobre todo naturalistas. Considerada simplista y eurocéntrica por geógrafos con responsabilidades de Estado en la organización política del Perú1, esta distribución longitudinal y tripartita del Perú en zonas geoclimáticas se estudia sin embargo desde la educación primaria.

1 Como, por ejemplo, Pulgar Vidal (1987), que después de criticar la visión tripartita, propone una clasificación alternativa primero en cinco y luego en ocho «Regiones Naturales», basadas en una 
Ministerios e instituciones del Estado la utilizan corrientemente para tratar todo tipo de temas. El Instituto Nacional de Estadísticas e Informática-INEI, por ejemplo, la emplea para describir asuntos de orden demográfico de carácter muy social y alejados de toda determinación natural. Ya que además de regiones naturales, esta partición se refiere también a zonas socioculturales: lo criollo o hispánico es representado por la costa, lo andino (o quechua) por la sierra y lo selvático (o indígena) por la selva. Es como si se considerara que la «mejor» manera para definir zonas sociológicas es a partir de zonas ecológicas en la medida en que enraízan la cultura en supuestos objetivos. Ahora bien, el contenido preciso de estas caracterizaciones tan generales y ambiguas queda implícito en cada uno de los discursos que las emplean, sean estos políticos, empresariales, diplomáticos o académicos. No hay espacio para profundizar este tema de gran complejidad y numerosas ramificaciones². En este texto me conformaré en defender que en el imaginario nacional peruano las tres regiones naturales no solo expresan zonas culturales (algo bien sabido y conocido y sobre lo cual no vale la pena insistir), sino también tiempos — como franjas horarias - de la historia de la identidad nacional peruana. Más precisamente episodios en la progresiva inclusión de los diferentes colectivos culturales al imaginario nacional.

La idea que quiero desarrollar es que este imaginario partió en el siglo XIX de un ideal hispano-costeño, para incorporar en la segunda mitad del siglo XX al mundo andino. Mi tesis es que a partir de la entrada en el siglo XXI, el Perú está incorporando el mundo amazónico como incorporó al andino anteriormente. Este proceso tiene aspectos sociales, culturales, políticos, económicos que no podré desarrollar aquí. Solo quisiera tratar uno de estos aspectos: la intrincada e inquietante relación entre la identidad cultural, las dinámicas sociales y la Antropología, una disciplina que más que explicar, muchas veces no hace más que reflejar. Trataré pues de Antropología, de la que conozco mejor, la amazónica, para mostrar cómo ha ido evolucionando de la misma manera que evolucionaba la percepción general sobre las sociedades amazónicas, gracias a su acción política, en el conjunto del país. Esto me llevará a abordar el asunto de las relaciones Andes-selva tan importantes en la antropología actual, y del rol de la costa entre ellas, fundamental desde mi punto de vista, pero apenas considerado.

combinación de conocimientos tanto tradicionales como geográficos, considerando las toponimias, las percepciones del clima, los datos en cuanto a flora y la fauna, los límites de los cultivos, las obras del hombre, los paisajes, que inspiró su acción política durante más de medio siglo. Ahora bien, de las ocho «regiones naturales» de Pulgar Vidal, siete se localizan en la costa y la sierra, mientras que la octava engloba la totalidad de la selva, hecho que muestra los mismos prejuicios de la división tripartita que el geógrafo critica. La clasificación de Pulgar Vidal, a pesar de que pretende inspirarse de la visión autóctona del espacio, no deja de ser una visión longitudinal del país, percibida no desde la costa como la tripartita, sino desde los Andes centrales, que no incluye varios aspectos de la variación ecológica latitudinal. Ver, para la noción de región transversal, Hocquenghem, 1998.

2 Para un análisis exhaustivo del tema ver Mesclier, 2001. 


\section{LA ANTROPOLOGÍA Y LA FRONTERA SELVA-SIERRA}

La antropología de las tierras bajas de América del Sur discurre, durante la segunda mitad del siglo pasado, con la convicción de que las sociedades sobre las que reflexiona son un archipiélago de pequeñas mónadas, aisladas unas de las otras, y al margen de la dinámica histórica. Al considerar estas colectividades como diseminadas y ahistóricas, estos estudios no hacían sino reflejar los vestigios de una larga tradición del pensamiento europeo que, desde José de Acosta, consideraba de una manera o de otra al indígena amazónico como sujeto pasivo de su destino y sometido a la determinación de la frondosa naturaleza circundante (Descola, 1985). Cierto es que esta supuesta incapacidad para «participar» de la historia se veía corroborada por un estado de aparente letargia política que los pueblos amazónicos mostraban en comparación con el activismo de otros pueblos indígenas americanos, aliados o no con los movimientos revolucionarios que surgieron entonces en toda Latinoamérica. Todo esto hacía de la Amazonía una región del mundo marginada y, paralelamente, un área cultural con una influencia muy marginal en el conjunto de la reflexión antropológica. Este momento, reflejado en la caracterización que hacen Julien Steward y Alfred Métraux de la Amazonía (refiriéndose en particular a la Amazonía andina), en el tercer volumen de la obra clásica Handbook of South American Indians (Steward, 1948), se perpetúa hasta el último cuarto del siglo $\mathrm{XX}^{3}$. A partir de entonces, una serie de antropólogos mejor formados empiezan a realizar trabajos de campo serios, y con posterioridad empiezan a aparecer los primeros resultados en forma de monografías. La producción de estos trabajos por profesionales europeos o norteamericanos, así como de los propios países sudamericanos, se desarrolla exponencialmente. Al mismo tiempo, los pueblos indígenas empiezan a organizarse y a sentir la necesidad de desembarazarse de antiguas tutelas. Misioneros, regatones, médicos y ONG son invitados a dejar paso a las nuevas organizaciones amazónicoindígenas, que se propagan por todo el subcontinente siguiendo la estela de algunas experiencias pioneras, como la Federación de Centros Shuar en Ecuador o el Consejo Aguaruna Huambisa en Perú. Estas organizaciones, todavía incipientes, abren paso a las grandes organizaciones nacionales, que como AIDESEP en Perú, representarán a decenas de federaciones étnicas hasta la creación de la COICA, la coordinadora de organizaciones indígenas de toda la cuenca amazónica. Pero lo que representa este proceso desde su misma etapa formativa, es una voluntad amerindia de aparecer, ya no como el resultado de los constreñimientos que la naturaleza particular de su ecosistema les inflige, o a lo mejor como objeto de procesos históricos ajenos, sino como verdaderos actores políticos que quieren y saben edificar su propio destino. Hoy las organizaciones indígenas amazónicas son un actor político principal en los países andinos y por supuesto en Perú.

3 Ver a este propósito Smith (2006: 70) y sobretodo los textos de Taylor, 1984; Descola \& Taylor, 1993 y Viveiros de Castro, 1996 para un análisis en profundidad de la historia de la antropología amazónica de la que me inspiro en este artículo. 
En cualquier caso, este empoderamiento de los pueblos amazónicos supone un cambio radical en la visión que la etnología tenía de ellos. Al considerar a los pueblos amazónicos actores de su propio destino, la Antropología pasa de observar una constelación de puntos independientes a interesarse por las relaciones que tienen entre ellos, y al hacerlo descubre que existe y ha existido una densa trama de intercambios, tanto simbólicos como concretos, que agrupa a conjuntos regionales que comparten mucho entre sí. Sin embargo, el análisis antropológico de estos espacios regionales interétnicos en la Alta Amazonía se encontraba con una frontera, no física, sino más bien conceptual, con las investigaciones de las tierras altas andinas. Todo separaba los estudiosos de las culturas andinas de aquellos interesados en las culturas amazónicas en los años 1970 o 1980, antes del aumento exponencial de las investigaciones sobre la Amazonía que empezó en la última década del siglo pasado. A sabiendas de que la siguiente simplificación pueda rayar la caricatura, podríamos decir que, en los Andes, el antropólogo tenía una formación en la encrucijada de los estudios agrarios, la etnohistoria, la historia colonial y la filología quechua, sensible a los movimientos campesinos y con una filia marxista: John Murra podría ser una figura representativa. Por su lado, con una inclinación política anarquista, la antropología amazonista perseguía la reflexión filosófica sobre la condición humana que podían representar las particularidades de las sociedades autárquicas, irredentas y al margen del embate colonial de las tierras bajas; la obra de Pierre Clastres sería un ejemplo paradigmático.

Estas fronteras reproducen un perjuicio que, como ha demostrado Fernando Santos Granero (1992), estaba presente desde la época prehispánica, y que los colonizadores adoptaron. En todo caso, desde el punto de vista de los europeos, esta dualidad de tipos de sociedades en función de su grado de evolución no es exclusivo del virreinato de Perú. Las primeras grandes sinopsis etnológicas realizadas por el poder colonial describen una jerarquía de sociedades que concierne no solo todo el continente, sino el mundo entero, siendo la diferencia entre las sociedades de tierras altas andinas y tierras bajas un ejemplo entre otros. En las conclusiones de la monumental Apologética historia, Bartolomé de Las Casas afirma que la mayoría de los indios de América y, por supuesto, los incas, los aztecas y las poblaciones nómadas de Florida que no rehúyen con violencia al contacto, no son bárbaros. Ahora bien, según él, los únicos pueblos que pueden ser considerados bárbaros de forma clara, simpliciter, como señala con esta expresión latina proveniente de la lógica, son los selváticos del Caribe, de Mesoamérica, y de las Tierras bajas sudamericanas. Es decir, aquellos que «viven desparcidos por los montes, huyendo de la conversación humana» (Las Casas, 1976: 641), que son crueles y feroces por una perversa inclinación suscitada por la degeneración de sus costumbres4.

Algunos decenios después, José de Acosta, que conocía muy profundamente la región andina, resumía en el Proemio de De Procudanda Indorem Salute su clasificación de sociedades, que corresponde con etapas de la evolución lingüística 
universal y que definen tres formas de barbarie. En las Indias orientales, los chinos y los japoneses, cuya forma de vida «no se aparta gran cosa de la recta razón» (Acosta, 1984 [1588]: 63), cuyo sistema de gobierno, leyes, ciudades y «lo que importa, uso bien reconocido de las letras» les sitúan en lo alto de la jerarquía después de la civilización. En la segunda categoría sitúa a incas y aztecas, con un alto grado de desarrollo legal e institucional y «que suplieron la escritura con tal derroche de ingenio» (Acosta, 1984 [1588]: 65) y otros grupos menores como los cacicazgos, sin alfabeto, pero con un lenguaje desarrollado. Para terminar, la tercera categoría agrupa a estos colectivos que, según Acosta, Aristóteles consideraba medio hombres, cuyo lenguaje no solo no poseía alfabeto sino que no permitía una comunicación eficaz. Para esto, se debe desarrollar una acción «para que aprendan a ser hombres, educarlos como a niños» (Acosta, 1984 [1588]: 69). Para el jesuita, a cada grado de desarrollo lingüístico le corresponden formas de gobierno más o menos desarrolladas así como tres niveles de observancia religiosa. Cualquier colectivo puede acceder a cualquiera de los estadios de desarrollo superior de forma gradual hasta llegar a la civilización, que se caracteriza por el perfecto manejo del lenguaje y la escritura alfabética como fundamento de un buen sistema de organización colectiva y cohesión religiosa. Su sistema de clasificación o su «filosófica», como él la denominaba, que se fundamenta en el uso del lenguaje y sus instrumentos de transcripción, supone en América una diferencia entre básicamente dos tipos de sociedades, las que tienen un sistema de organización o jefatura y las que no. Si los incas se encuentran entre las primeras, los pueblos amazónicos se sitúan en estas últimas (Acosta, 1979 [1570]: 63-69)5.

Todo esto para decir que el cisma entre tierras altas y tierras bajas en Sudamérica proviene de un cisma epistemológico profundamente anclado en la tradición intelectual europea, que encontró además, como ya he mencionado, un aval en las elites andinas del Incanato que consideraban la selva como lo opuesto a la sierra. Por esta razón el intento de superarlo es meritorio. Hay que esperar la publicación del célebre volumen de France-Marie Renard-Casevitz, Thierry Saignes y Anne Christine Taylor, traducido al español en dos tomos como Al este de los Andes (Renard-Casevitz et al., 1988), y los textos de Richard Smith6, para que esta frontera conceptual y disciplinar se cuestione, para que la supuesta frontera geográfica, ecológica y social empiece a ceder también, y permita apreciar las continuidades sociales e históricas entre las dos regiones, sin negar por supuesto sus particularidades — que las hay y son muchas_, ni la existencia de los propios pueblos indígenas portadores cada uno de su propia especificidad. Para percibir la importancia que significaba este desafío en aquel momento, no hay que olvidar la famosa referencia de Richard Smith a la conversación con su entonces profesor John Murra: «olvídate de esta línea de investigación. Los yánesha son amazónicos mientras que los otros son andinos» (Smith, 2011: 220). En cualquier caso, este gesto teórico da inicio a un numeroso grupo de trabajos comparativos entre

5 José de Acosta analiza con detalle esta sinopsis en el Libro VI (Acosta, 1979 [1590]: 280-318) de Historia natural y moral de las Indias.

6 Por ejemplo, Smith, 1983. 
Amazonía y sierra, que permiten desenclavar en parte cada una de las tradiciones y posibilitan un inicio de convergencia de intereses.

\section{EL TERCERO AUSENTE: LA COSTA}

A pesar de los esfuerzos avanzados por los estudios precedentes para terminar con esta frontera conceptual, parece que los estudios amazónico-andinos no han superado totalmente la división entre selva y sierra como dos unidades a priori del análisis social. De alguna forma, podríamos decir que la perpetúan por el simple hecho de presentarlas como tales. Es decir: explorando las interacciones en estas dos unidades, Amazonía y sierra, no se hace otra cosa que ratificar su existencia. Una forma de avanzar en la disolución de estas fronteras geoacadémicas es introducir el tercer ausente: la costa. Porque no tiene sentido limitarse a destacar las relaciones Andes-Amazonía, y obviar al mismo tiempo el vínculo profundo entre las sociedades de la sierra y las de la costa, sin hablar de la continuidad entre estas dos regiones en muchos lugares de la geografía de Ecuador y de Perú. Efectivamente, si analizamos los flujos de intercambio material y simbólico entre Sierra y Amazonía, no podemos contentarnos con desplazar el límite más al oeste, allí donde se supone que finaliza la sierra, allá donde esta última se encuentra desde siempre en una interacción intensa con la costa. Esta conexión se ha exacerbado en la actualidad, debido a la promoción de vías de transporte que enlazan, sin pasar por Lima en el caso peruano, a ciudades de la costa con ciudades de la selva por la sierra. El resultado ya no es un sistema de dos ámbitos - tierras altas por un lado y Amazonía por el otro-, con puntos de contacto que se deben explorar, sino una complejidad de relaciones que configuran una dinámica de orden regional integrando la costa.

Lo más curioso es que los trabajos de Anne Chistine Taylor en el eje que llamaré ecuato-peruano (una región situada en la franja de la costa a la Amazonía alrededor de la actual línea fronteriza), y los trabajos de Richard Smith en el eje que llamaré central-peruano (una región que se extiende de la selva central peruana a la costa central en una zona donde ahora se ubica Lima), realizados en el contexto de las relaciones entre Andes y Amazonía, ya incluyeron con toda naturalidad la costa. Refiriéndose a la zona del sur de los Andes ecuatorianos, Taylor señalaba:

En definitiva, la depresión muy marcada de la cordillera en el sur de la zona andina ecuatorial, la presencia de grandes valles transversales, la del río Catamayo y la del río Puyango, por último la reducida distancia que separa aquí la costa pacífica de la cuenca amazónica, por la escotadura del Chinchipe, hace de esta región una zona privilegiada para los contactos culturales y los flujos de población (Taylor, 1988: 197).

Por su lado, Smith declaraba: «El espacio histórico cultural yánesha es una franja transversal que se extiende por ambas vertientes de los Andes, desde la llanura amazónica (Pachitea-Alto Ucayali) hasta el Océano Pacifico (Chillón, Rímac, Lurín y Chilca)» y sugiere un poblamiento proto-yánesha de la costa que coincide con el periodo formativo de la cultura Lima (200-700 d. C.) (Smith, 2011: 238). 
Estas conexiones entre Amazonía, sierra, y costa en los trabajos de Taylor y Smith no se deben solo a la gran lucidez de estos autores. Creo que se deben también a que es precisamente en los lugares donde estos antropólogos trabajan que las conexiones históricas entre estas tres regiones se han dado con más frecuencia e intensidad. Las razones son muchas y combinan aspectos ecológicos, geográficos, históricos, sociales y culturales a los que se refiere Taylor en la cita precedente. Destacaría uno que me parece importante, porque agrupa todos estos aspectos en un solo factor: la disposición de las cuencas hidrográficas. Como ya he mencionado, hay esencialmente dos grandes ejes este-oeste: en el norte, el corredor ecuatoperuano conformado por la cuenca del Marañón lado selva y las cuencas lado costa de Guayas, Tumbes y Jequetepeque; más al sur, el corredor central conformado por la cuenca del Ucayali que discurre este-oeste sobretodo por los ríos Perené y Pachitea lado selva, y las cuencas vertiente costa del Chillón, Rímac, Lurín y Chilca7. Entre estos grandes corredores tenemos una elevación de la cordillera de los Andes que la hace más difícilmente franqueable. Más al sur del corredor central, y más al norte del corredor ecuato-peruano, la cuenca amazónica se aleja, como es lógico, por su forma elíptica. En todo caso, la diferencia entre la altura de los Andes en la zona ecuato-peruana, muy baja, y la central, considerable, pueden hacer pensar que no es tanto la altura de la cordillera lo que permite o impide el contacto; lo fundamental en la posibilidad de establecer relación sería el curso de los ríos por el lado amazónico, Marañón, Ucayali y los afluentes de ambos, como auténticos conductores de civilización. Como si la extensa red hidrográfica que conforma la cuenca amazónica en toda su extensión fuera una inmensa trama de captación y transmisión cultural. Y que esta inmensa red encontrara en sus puntos de contacto con el litoral marino un lugar de esplendor, como fueron la Lima o la costa norte peruana en el período precolombino. Que sean los ríos los ejes de comunicación, no solo física sino también cultural y simbólica, no es nada extraño desde un punto de vista amazónico, donde la red hidrográfica es la trama por la cual fluye la información cultural y las relaciones sociales. Ignoro si se trata de la misma relevancia fluvial en la costa y la sierra, pero creo que esto debe encontrarse todavía más acuciado por el carácter agropecuario de su economía: el contraste entre los vergeles de huertas y frutales en las orillas de los ríos costeños, y el desierto extremo en las áreas interfluviales son la prueba más evidente de esto. En todo caso, en la zona costera de estos corredores esto-oeste nos encontramos hoy en día con los vestigios arqueológicos más importantes de las culturas de la costa.

7 Se debe precisar que los ríos amazónicos, sobretodo en la parte del corredor central donde se erigen los flancos montañosos escarpados de los Andes, no permiten, como es de suponer, atravesar la cordillera. En estas zonas elevadas no es posible seguir los cursos de agua y, en el pasado, el acceso dependía de encontrar formaciones geológicas que permitan abrir caminos por la cresta de las montañas hasta la puna, donde el paisaje es abierto y llano. Es la combinación entre la vía fluvial y estos senderos que siguen la cresta hasta llegar a los valles bajos, que ha permitido el tránsito de la selva a la puna y de esta a la costa. 


\section{EL EJE LATITUDINAL}

Al explorar los contactos históricos entre la costa y la selva en las conclusiones de su contribución en Al Este de los Andes, Anne Christine Taylor (1988: 295-305) afirma que, a pesar de la irrupción de las rutas de expansión y control del espacio del poder estatal, incaico primero y colonial después, de orientación longitudinal, las redes latitudinales de intercambio de bienes y servicios entre el oriente selvático y la costa, se mantuvieron entre las sociedades dominadas y marginadas por los poderes imperiales. La pregunta a la que me gustaría responder es si estos ejes marginales este-oeste siguen en la actualidad y continúan canalizando, con las carreteras llamadas marginales, una actividad específica. Si estas vías continúan activas, nos encontraríamos con la orientación longitudinal, nortesur, de los caminos y corredores del poder incaico, colonial y republicano, que atravesaría los antiguos flujos fluviales este-oeste, pero que no los disolvería. Estos ejes latitudinales continuarían presentes entre las poblaciones modestas, de una economía de subsistencia campesina, dependientes de intercambios locales, al margen de la gran economía de mercado. A la pregunta de cuál es la actualidad de estos flujos este-oeste, yo respondería que es innegable la existencia de un movimiento muy intenso en el eje entre Piura y Chiclayo en la costa y Sta. María de Nieva y San Lorenzo en la selva, que he tenido ocasión de observar durante mis estadías en la zona. Una gran cantidad de población costeña piurana, formada por pequeños comerciantes y algunos funcionarios menores de salud o educación, se encuentra viviendo en las ciudades emergentes de la selva. En sentido opuesto, es también frecuente que la población amazónica, indígena o no, pase períodos en las ciudades de la costa norte, a menudo para realizar los estudios de secundaria o por trabajo. También, unos y otros, costeños y amazónicos, van del campo a la ciudad, y esto desde cualquier punto del norte peruano, a cualquier ciudad del norte del Perú, sea selva, sierra y costa. En este flujo no encontramos a los grandes empresarios y altos funcionarios que tienen a Lima como punto de referencia. Estos últimos transitan más bien entre las grandes ciudades costeras y Lima, y más recientemente, por cierto, entre la capital y algunas ciudades de la sierra que se han desarrollado mucho al amparo de la industria minera, como Cusco, Pasco, Huancavelica o Huancayo, por solo citar algunos ejemplos. En otras palabras, la hipótesis de una orientación norte-sur de los sectores dominantes y una orientación este-oeste de los dominados, vigente en el período prehispánico y colonial, parece seguir activa hoy en día.

El eje latitudinal orienta así una circulación de personas y familias de bajos recursos que no pueden emprender una implantación demasiado arriesgada en la capital del país, y que prefieren buscar oportunidades en el eje este-oeste. Si pueden, si disponen de recursos y contactos, la población piurana no va a la selva, aunque esta aparece como un mundo de oportunidades cuando no se tienen. Como no puedo demostrar todo esto con otro tipo de datos, me permitiré hacer referencia a una fuente un poco insólita en un artículo de este tipo: una obra literaria. La acción de la segunda novela del escritor peruano Mario Vargas Llosa (1966) titulada 
La casa verde, transcurre entre dos escenarios: Piura, en el desierto de la costa norte, y la selva amazónica peruana, principalmente en Santa María de Nieva. No voy a resumir la obra conocida de muchos, solo decir que los protagonistas son gendarmes sin grado, como Lituma, que se traslada de Piura a Sta. María de Nieva y se casa con una indígena aguaruna, Bonifacia, Ilamada la «selvática». Otros protagonistas son personas de bajos recursos y dudosa reputación, como La Chunga y la propia Bonifacia, caucheros medio bandidos como Fushia y comerciantes de pacotilla como Reátegui, todos unidos en una narración cuyo nervio son los ríos Marañón y Amazonas y sus afluentes, pero que continúa hacia el oeste hasta llegar a Piura. Leí esta obra en San Lorenzo del Marañón, la otra gran población río abajo después de Nieva, en los años noventa al inicio de mi trabajo de campo etnográfico. Su lectura me sugirió una actualización, que realicé personalmente, preguntado a los vecinos de San Lorenzo informaciones sobre los personajes que aparecen en la trama y que confirman que Vargas Llosa también realizó un trabajo de campo en la región, recopilando historias, leyendas y rumores que le contaba la gente, para nutrir su novela. En todo caso, este escritor arequipeño pero criado en Piura, pone en evidencia, consciente o inconscientemente, la intensidad de este eje costa-selva y la naturaleza marginal de los que viven de y en él.

Si la perspectiva de los migrantes costeños se refleja muy bien en la obra del célebre escritor peruano, trabajos recientes de la Antropología permiten comprender cómo es vivido el tránsito por este eje latitudinal, en particular entre el Alto Marañon y la ciudad costeña de Chiclayo, por los selváticos y en particular por los indígenas awajun (Romio, 2016). Según Silvia Romio, se sabe que ya desde los años 1930 y en el marco de programas formativos de Iglesias protestantes, varios awajun viajaron y residieron durante meses con familias evangélicas de esta última ciudad. Aunque el objetivo de los misioneros era posibilitar a una élite awajun la interiorización del mensaje bíblico, para los indígenas estas experiencias tenían otro significado. En estos viajes se trataba de adquirir conocimientos del mundo moderno, hispánico y dominante. Es así como los primeros viajeros se convirtieron, a su retorno en el Marañón, en héroes fundacionales de la «época moderna», por ser los introductores de nuevos significados existenciales que se conjugaban con los modelos de vida tradicionales indígenas. Estas estadías siguen en la actualidad y permiten a los jóvenes indígenas acceder a una educación de mayor calidad, aprender el español y familiarizarse con la cultura nacional peruana. Gracias a este desplazamiento latitudinal que adquiere un verdadero significado iniciático con objetivos paralelos a la búsqueda de visiones tradicionales, los jóvenes viajeros indígenas incorporan los saberes que les permiten, de regreso a la selva, ejercer el liderazgo.

En el caso peruano, es cierto que estos flujos no son tan importantes en términos demográficos como el éxodo rural de toda la selva y el Perú entero a Lima, que concentra hoy casi 9 millones en un país de 30 millones. Se trata en efecto del gran flujo de migración de la selva a la costa hoy en día en Perú y que se inserta en una tendencia a la urbanización de las poblaciones rurales e indígenas de la Amazonía. El crecimiento exponencial de las poblaciones y ciudades amazónicas, algunas 
de las cuales eran pequeños asentamientos hace solo algunos años, se debe al aporte sustancial de indígenas, junto al de migrantes provenientes de regiones no amazónicas. Este éxodo llega también hasta las grandes capitales y conurbaciones de la costa, con una cantidad cada vez más numerosa de población de origen amazónico, que pasa a menudo por periodos más o menos largos en ciudades intermedias, capitales de provincia o poblaciones menores, no necesariamente situadas en la selva.

La presencia de indígenas en las ciudades no ha pasado desapercibida a la antropología amazónica, que empieza a interesarse por una realidad cada vez más patente y que obliga a revisar les esquemas analíticos clásicos. No es el momento de abordar este tema aquí; solo señalar que la presencia de población amazónica en Lima se debe sobretodo a razones económicas, debido a la presión causada sobre sus territorios por la colonización, asi como educativas y religiosas (las misiones y sus Iglesias tienen las sedes en Lima). Se debe también a razones organizativas del movimiento político indígena: un fenómeno en buena parte urbano, aunque defienda los derechos de territorios y poblaciones rurales. Las sedes de las organizaciones, la vida de los dirigentes, las reuniones y asambleas se dan en Lima, y esto no es anodino en términos de adopción de pautas y conductas. Además, una vez instalados en las ciudades y capitales, los líderes indígenas se organizan. Constituyen asociaciones, promueven una presencia cultural, reclaman derechos de asentamiento, eligen líderes, reproduciendo con todo ello los modelos que les son familiares y que se han cuajado en formas de organización seculares y en la historia reciente de procesos organizativos, que se han dado en las comunidades selváticas de las que provienen. El asentamiento shipibo de Cantagallo, a orillas del Rímac, cerca del palacio de gobierno en Lima, reclamando la titulación como comunidad nativa y exigiendo una escuela bilingüe, es el ejemplo más notable8. Diferentes fuentes 9 coinciden en señalar que los grupos étnicos presentes provienen de toda la Amazonía, siendo los awajun, kokama-kukamiria, shawi, ashaninka, yánesha, nomatsiguenga y shipibo-konibo los más numerosos. Se trata de pueblos situados en su mayoría en la primera línea del frente de colonización, es decir, con una parte del territorio en ceja de selva. Esto no es por supuesto un azar y nos permite avanzar una nueva hipótesis: el contacto con el frente colonial supone el expolio territorial y degradación del ecosistema y obliga a las poblaciones amazónicas a migrar en razón de la merma de la calidad de vida, pero proporciona también los recursos culturales para iniciar un éxodo rural a la capital. En efecto, este contacto permite a una vanguardia de jóvenes amazónicos aprender el español y otros conocimientos necesarios para desenvolverse con soltura cuando Ilegan a las grandes capitales. Una vanguardia,

8 Para una perspectiva más amplia de la importancia del movimiento indígena en la urbanización de los amazónicos, algunos artículos del libro colectivo editado por Surrallés et al. (2016), aportan una sustancial información y análisis. Por lo que se refiere a los shipibos de Cantagallo ver, en el mismo volumen, el artículo de Espinosa, 2016.

9 Ver por ejemplo el Informe Diagnóstico situacional de los pueblos indígenas amazónicos en Lima metropolitana, 2013. 
porque estos migrantes corresponden a la juventud amazónica más preparada en términos educativos y culturales, lo que constituye una pérdida irreparable para la selva pero un aporte extraordinario a la cultura urbana del país.

\section{4. ¿UNA REVOLUCIÓN CULTURAL AMAZÓNICA?}

La presencia de población amazónica en Lima, migrantes, pero también miembros de organizaciones de defensa de los derechos indígenas, artistas o estudiantes, ha sido seguramente el punto de arranque de la incorporación de la Amazonía en el imaginario nacional del Perú, un asunto esencialmente limeño, dado el gran centralismo imperante. Mientras el Ministerio de Cultura invierte en el «camino del Inca» como patrimonio cultural del Perú y trama espacial longitudinal de vertebración ideológica de la nación, la sociedad constructora de opinión, las élites culturales del país, se interesan por la selva y el eje latitudinal. No sé si se le puede llamar una revolución cultural amazónica, pero si un movimiento de baja intensidad, aunque no por ello menos tenaz, imparable e irreversible. Es difícil saber cómo y cuándo empezó, pero una serie de grandes exposiciones de arte amazónico como El Ojo verde en la Fundación telefónica en 1998, o la exposición La serpiente de agua, en la primera gran acción cultural en la Estación de Desamparados, inaugurada por el mismo presidente de la Republica en 2003, marcan sin duda uno de estos momentos fundacionales. Otras grandes exposiciones han tenido lugar con posterioridad. Además, se podría hablar de la música amazónica, de una lista importante de artistas plásticos que reivindican una estética amazónica, y, por supuesto, de toda una serie de iniciativas activistas para defender la ecología y los derechos de los pueblos indígenas amazónicos (inscritas también en una agenda global que influye en las iniciativas nacionales) que hasta hace poco tiempo eran muy poco conocidas y apoyadas por las fuerzas progresistas peruanas.

En otras palabras, se trata de una «movida selvática», como la denomina Christian Bendayán, artista plástico emblemático de esta vanguardia cultural amazónica y director del Instituto Nacional de Cultura en la ciudad de Iquitos. En una entrevista a la BBC, Bendayán señala que «los protagonistas de este movimiento son tanto artistas plásticos urbanos como él mismo, como artistas nativos que adquieren prestigio y notoriedad, como Pablo Amaringo, un chamán de la selva que consiguió transmitir el mundo del Ayahuasca en su obra pictórica». Considera asimismo la exposición El Ojo verde, curada por Gredna Landolt, como la «exhibición-madre que cambió la imagen de la Amazonía» y añade que «en esa misma época confluyeron en la capital peruana distintos grupos de artistas que apelan tanto a los gustos más sofisticados como a los más populares. Uno de ellos fue el grupo musical llamado Kaliente, que en 2005 obtiene un éxito extraordinario con la pieza de cumbia amazónica titulada El embrujo». Bendayán añade algo importante en el Perú actual, como es la gastronomía, con el restaurante Malabar, «uno de los más refinados de la capital y el primero de ese nivel en incluir 
ingredientes provenientes de la Amazonía, relegados hasta entonces a modestas cocinas provincianas» 10 .

En definitiva, la Amazonía ha entrado en el imaginario cultural nacional; el Perú se descubre país amazónico, como se descubrió país andino en el siglo pasado. Sin embargo, la revolución estético-cultural andina era sobretodo literaria y política, con sus movimientos políticos que se reclamaban marxistas. La amazónica, por su lado, es más visual que literaria, más activista que política, más verde que marxista, pero como la andina, cambiará el imaginario nacional peruano. Un ejemplo es la película documental del gran director Javier Corcuera, Sigo Siendo (2012), que repasa la excelsa música tradicional peruana para reflexionar sobre la identidad nacional, como él mismo reconoce en la web principal de la producción11:

Esta película habla de esas personas que llegaron a la gran ciudad y nunca se desprendieron de su identidad, que siguieron cantando en su lengua, que mantuvieron una manera única de tocar la guitarra, el violín, el arpa, el cajón, una manera de contar historias, de decir quiénes son. Desde la música y desde los grandes maestros de nuestra música, la película cuenta la diversidad de la cultura peruana, la complejidad del país, su pasado y su presente.

O, como dice la sinopsis de la película también en la web oficial:

Sigo siendo (Kachkaniraqmi) es una película de personajes, de personajes que son parte de un país. Esta película habla de música y de músicos, pero no es una película estrictamente musical, es una película de historias personales aparentemente muy lejanas, historias que se buscan en un país que también intenta encontrarse y dibujar su identidad.

Esta película, quizá el trabajo reciente más importante sobre este imaginario identitario peruano, empieza en la Amazonía con una canoa en un rio brumoso y una mujer shipiba, de nombre Roni Wano que significa «Madre del agua», cantando en solitario para representar, de alguna forma, la quintaescencia del Perú. Aunque, esto sí, el título de la película esta traducido solo al quechua, lo que refleja la perenne y espontánea preeminencia de lo andino en la constitución del imaginario nacional.

\section{A MODO DE CONCLUSIÓN}

En resumen, los estudios amazónicos de los países andinos se han interesado estos últimos decenios en analizar las relaciones de las poblaciones selváticas orientales con los Andes. Estas investigaciones han permitido comprender mucho mejor las articulaciones entre estas dos regiones a pesar de las tradiciones intelectuales distintas de los investigadores que han trabajado en una u otra región. Esta

10 https://www.bbc.com/mundo/cultura_sociedad/2010/06/100611_peru_identidad_amazonia, Lima, por una identidad más salvaje, Javier Lizarzaburu BBC Mundo, Lima

11 https://sigosiendo.pe/ 
orientación ha sido tan enriquecedora que es el momento de proseguir con un análisis de las articulaciones entre la Amazonía y la costa pacífica. La inexistencia de una continuidad espacial entre la región costera y la amazónica puede hacer pensar que el interés por desgranar las relaciones entre las dos zonas sea menos legítimo que entre la sierra y la selva, unidas por la ceja de selva. Sin embargo, hay varias consideraciones que nos pueden indicar el interés capital de esta idea.

Desde un punto de vista geográfico, la cordillera de los Andes no es, en todas partes, una frontera física inexpugnable. En cualquier caso, la diversidad de ecosistemas puede generar dinámicas de intercambio de bienes y, por lo tanto, movimiento de ideas y personas. Además, la orientación este-oeste de la mayoría de los cursos fluviales incitan las poblaciones a transitar latitudinalmente $y$, en ambos sentidos, de la costa a la selva. Por otro lado, la homogeneización establecida por la expansión incaica en las altas tierras, ha dejado quizá similitudes entre las sociedades indígenas, costeras y selváticas del pasado. En el presente, como lo prueba la etnología de las poblaciones indígenas costeñas allí donde permanecen, las proximidades y las relaciones entre costa y Amazonía son muchas (Ventura i Oller, 2012). Las estrechas conexiones que existen entre las poblaciones costeñas entre sí, las andinas entre sí y las amazónicas entre sí, de diferentes latitudes, favorecidas por compartir una ecología, un tránsito fluido (facilitado por vías naturales, como los callejones interandinos o los ríos navegables, o artificiales, como la carretera panamericana), y una historia similar, están fuera de duda. Sin embargo, existen también una serie de relaciones muy intensas entre segmentos regionales transandinos, que unen costa, sierra y selva en ámbitos de una profundidad histórica y densidad cultural considerables (Ventura i Oller, 2011). Como demuestran algunos análisis ya realizados de conjuntos etnohistóricos, aparte de las relaciones norte-sur dentro de cada una de las clásicas regiones costera, andina y amazónica, que han marcado la formación y los intereses de los estudiosos, existen unos ejes este-oeste que atraviesan la sierra, de la costa a la selva oriental y viceversa. Sobre estos antiguos flujos latitudinales, se han sobrepuesto dinámicas migratorias actuales, donde es fácil encontrar trabajadores amazónicos de la selva en la región costeña paralela, y a la inversa, movimientos que facilita el desarrollo de las vías de comunicación este-oeste. En cualquier caso, dada la masiva afluencia de población amazónica, incluida la indígena, en las grandes ciudades costeras, hoy en día es imposible seguir hablando de la Amazonía sin tener en cuenta la costa.

Para no terminar, una breve reflexión que atañe a la antropología amazonista de la región andina y de alguna forma a la disciplina en general. Porque hay algo inquietante en esta coincidencia entre aproximaciones científicas, áreas regionales, movimientos políticos y tendencias culturales examinadas brevemente en este ensayo. La antropología andina exulta en los años 1970 y 1980 con los trabajos de John Murra como uno de los referentes principales, cuya perspectiva marxista enlaza con el auge de los movimientos políticos de esta tendencia. Hoy en día, la antropología andina ya no suscita el mismo interés que en el siglo pasado de la misma manera que no lo hace el marxismo, casi desparecido del panorama tanto político como antropológico. A su vez, la Amazonía parece haber 
tomado el relevo en el interés público y antropológico que suscita. Esta área geográfica y cultural aparece ahora asociada a la ecología política y al reclamo de reconocimiento de minorías étnicas, asuntos que despiertan la solidaridad tanto a nivel nacional como global.

La pregunta que nos podríamos hacer es cuál es el rol de la Antropología en el análisis y descripción de la realidad en general y del imaginario nacional en particular, si esta crónica del último medio siglo es acertada. No es, en todo caso, el rol de una disciplina guiada por la objetividad y la independencia de criterio, aunque tratándose de una ciencia social, es mejor que así sea. Dicho de otro modo, es mejor que, por un lado, la Antropología no se vea obsesionada por una aspiración a una objetividad imposible de los hechos sociales y que, por el otro, permanezca atenta y conectada con el entorno social y político en la que se desarrolla. Ahora bien, la cuestión sería si esta relación de la historia de la Antropología con su entorno refleja el carácter de un pensamiento de vanguardia, de una disciplina que posee las capacidades de introducir nuevas preocupaciones, de circunscribir los verdaderos problemas y de introducir perspectivas originales para describirlos. $O$ se trata en realidad de una actividad académica, simple comparsa de ideologías políticas y efectos de moda culturales, nacidos para desvanecerse cuando su tiempo pasa y son sustituidos por nuevas tendencias. La respuesta sería que la Antropología puede ser las dos cosas, cayendo sobre cada uno de los que la ejercemos la responsabilidad de medir bien la cantidad de cada uno de los dos ingredientes en las reflexiones que realizamos.

\section{Referencias citadas}

ACOSTA, J. de, 1984 [1588] - De procuranda Indorum salute. Pacificación y colonización, 2 v.: XXIII, 734 pp., XXIII, 521 pp.; Madrid: Consejo Superior de Investigaciones Científicas. Edición por L. Pereña ... et al.

ACOSTA, J. de, 1979 [1590] - Historia natural y moral de las Indias: en que se tratan de las cosas notables del cielo, y elementos, metales, plantas: y animales dellas: y los ritos, y ceremonias, leyes y gobierno de los Indios, 444 pp.; México: Fondo de Cultura Económica. Edición preparada por Edmundo O'Gorman.

DESCOLA, P., 1985 - De I'Indien naturalisé à I'Indien naturaliste : sociétés amazoniennes sous le regard de l'Occident. In: Protection de la nature : histoire et idéologie. De la nature à l'environnement (A. Cadoret, ed.): 221-235; París: L'Harmattan.

DESCOLA, P. \& TAYLOR, A. C., 1993 - Introduction in «La remontée de l'Amazone». L'Homme, 33 (126-128): 13-24.

ESPINOSA, O., 2016 - La política indígena en la ciudad: el caso de las comunidades urbanas shipibo-konibo. In: Apus, caciques y presidentes; Estado y política indígena en los países andinos (A. Surrallés, O. Espinosa \& D. Jabin, eds.): 97-117; Lima: IWGIA, IFEA, PUCP. 
HOCQUENGHEM, A. M., 1998 - Para vencer la muerte. Piura y Tumbes. Raíces en el bosque seco y en la selva alta - Horizontes en el Pacífico y en la Amazonía, 445 pp.; Lima: IFEA, INCAH, CNRS.

INFORME DIAGNOSTICO SITUACIONAL DE LOS PUEBLOS INDÍGENAS AMAZÓNICOS EN LIMA METROPOLITANA, 2013 - Lima: Terra Nuova, Centro Amazónico de Antropología y Aplicación Práctica-CAAAP, Municipalidad Metropolitana de Lima.

LAS CASAS, B. de, 1967 [1566] - Apologética historia sumaria, 2 tomos; México: Universidad Nacional Autónoma de México, Instituto de Investigaciones Históricas. Edición preparada por Edmundo O'Gorman, con un estudio preliminar, apéndices y un índice de materias.

MESCLIER, E., 2001 - De la complementariedad a la voluntad de "aplanar los Andes": representaciones de la naturaleza y pensamiento económico y político en el Perú del siglo XX. Boletín del Instituto Francés de Estudios Andinos, 30 (3): 541-562.

PULGAR VIDAL, J., 1987 - Geografía del Perú, 244 pp.; Lima: PEISA (Novena edición).

RENARD-CASEVITZ, F.-M., SAIGNES, T. \& TAYLOR, A. C., 1988 - Al este de los Andes: relaciones entre las sociedades amazónicas y andinas entre los siglos XV y XVII, 2 vols., $322+266$ pp.; Lima-Quito: Institut français d'études andines, Abya-Yala.

ROMIO, S., 2016 - El viaje hacia la ciudad: caminos de vida, camino para el poder. La nueva forma del ritual de iniciación entre los Awajún (1930-1960). In: Apus, caciques y presidentes. Estado y política indígena en los países andinos (A. Surrallés, Ó. Espinosa \& D. Jabin, eds.): 61-80; Lima: IWGIA, IFEA, PUCP.

SANTOS-GRANERO, F., 1992 - Etnohistoria de la Alta-Amazonia. Siglo XV-XVIII, 305 pp.; Quito: Abya-Yala.

SMITH, R. 1983 - Hierarchy and Equality in the Peruvian Lowlands: Some Aspects of the Social and Religious Organization of the Amuesha, 71 pp., Cambridge, Manuscrito no publicado.

SMITH, R., 2006 - Where Our Ancestors Once Tread: Amuesha Territoriality and Sacred Landscape in the Andean Amazon of Central Peru. In: Être Indien dans les Amériques (C. Gros \& M.-C. Strigle, eds.): 69-84 ; París: Éditions de l'Institut des Amériques \& Éditions de l'Institut des Hautes Études de l'Amérique latine.

SMITH, R., 2011 - ¿Un sustrato arawak en los Andes centrales? La historia oral y el espacio histórico cultural yánesha. In: Por donde hay soplo. Antropología Amazónica en los Países Andinos (J.-P. Chaumeil, Ó. Espinosa de Rivero \& M. Cornejo Chaparro, eds.): 219-254; Lima: IFEA, PUCP, CAAAP, EREA.

STEWARD, J. H., ed., 1948 - The Tropical Forest Tribes, 1011 pp.; Washington, DC: Smithsonian Institution. Handbook of South American Indiens, vol. 3.

SURRALLÉS, A., 2015 - Siguiendo el sol, surcando el río: las relaciones entre la Amazonía y la costa en la región andina. Bulletin de l'Institut français d'études andines [En línea], 44 (1): 168-175. URL: http://journals.openedition.org/bifea/7463.

SURRALLÉS, A., ESPINOSA, Ó. \& JABIN, D. (eds), 2016 - Apus, caciques y presidentes; Estado y política indígena en los países andinos, 273 pp.; Lima: IWGIA, IFEA, PUCP.

TAYLOR, A. C., 1984 - L'américanisme tropical, une frontière fossile de l'ethnologie ? In: Histoires de l'anthropologie XVI, XIX siècles (B. Rupp-Eisenreich, ed.): 213-233; París: Klincksieck Librairie.

TAYLOR, A. C., 1988 - Al este de los Andes. Relaciones entre las sociedades amazónicas y andinas entre los siglos XV y XVII. Tomo II, 266 pp.; Lima-Quito: Institut français d'études andines, Abya-Yala. 
Costa, sierra y selva: franjas geográficas, zonas culturales y episodios nacionales

VARGAS LLOSA, M., 1966 - La casa verde, 430 pp.; Barcelona: Seix Barral.

VENTURA I OLLER, M., 2011 - Redes chamánicas desde el punto de vista Tsachila. Nuevo Mundo. Mundos Nuevos. Nouveau Monde. Mondes Nouveaux, Debates, 2011. http://nuevomundo.revues.org/61200

VENTURA I OLLER, M., 2012 - En el cruce de caminos. Identidad, cosmovisión y chamanismo Tsachila, 306 pp.; Quito: FLACSO-Ecuador, Abya Yala, IFEA, Universidad Autónoma de Barcelona.

VIVEIROS DE CASTRO, E., 1996 - Images of Nature and Society in Amazonian Ethnology. Annual Review of Anthropology, 25:179-200. 